\title{
Towards operational hydrological model calibration using streamflow and soil moisture measurements
}

\author{
$\underline{\text { Yuxi Zhang }}{ }^{1}$, Yuan Li ${ }^{1}$, Jeffrey P. Walker ${ }^{1}$, Valentijn R. N. Pauwels ${ }^{1}$ and Mahshid Shahrban ${ }^{1,2}$ \\ ${ }^{1}$ Department of Civil Engineering, Monash University, Clayton, VIC, 3800, Australia \\ ${ }^{2}$ CSIRO Land and Water Flagship, Highett, 3190, VIC, Australia \\ Email: yzha601@gmail.com
}

\begin{abstract}
Timely and reliable flood forecasting is critical for flood warning delivery and emergency response. As core components of an operational forecasting system, hydrological models are typically calibrated using streamflow measurements to minimize parameter uncertainties. The rapid development of earth observation techniques provides opportunities to obtain soil moisture information. As catchment discharge is strongly related to soil moisture, there is a possibility to improve streamflow forecasts by using soil moisture measurements for model calibration. The use of soil moisture observations has attracted increasing attention, however, there have been a limited number of studies.
\end{abstract}

This study aims to assess the impact of integrating soil moisture measurements for model calibration on the forecast skills of hydrological models. Experiments were implemented in the Adelong Creek $\left(157 \mathrm{~km}^{2}\right)$ and the Upper Kyeamba Creek $\left(190 \mathrm{~km}^{2}\right)$ catchments of the Murrumbidge Basin using a lumped rainfall-runoff model named GRKAL (modèle du Génie Rural Kal). Two calibration scenarios are performed: 1) a traditional streamflow-only-calibration; 2) a joint-calibration using both streamflow and in-situ soil moisture measurements. Outcomes are evaluated in a hind-casting mode for both a calibration and independent validation period.

Results show that, for the Adelong catchment, the joint-calibration led to a slightly worse match between the simulated and observed streamflow with a Nash-Sutcliffe (NS) value of 0.8173 , as compared to the streamflow-calibration scheme (achieved a NS value of 0.8443 ) alone in calibration period. During the validation period, the joint-calibration achieved a NS value of 0.7952 , performing better than the streamflowcalibration scheme which gives a NS value of 0.7586 . This result indicates that although introducing the soil moisture measurements to the objective function lead to a sub-optimal match of simulated streamflow to the observed data during the calibration period, there exists the possibility that joint calibration potentially optimized the model parameters to be more realistic, resulting a more precise prediction in the validation period. However, for the Kyeamba catchment, the results tend to be worse: NS values derived from jointcalibration was less than that obtained by streamflow-calibration in both calibration and validation period. This may relate to the unphysically based model structure, equal-weighted objective function, and various sources of uncertainties.

In terms of the soil moisture prediction, it is consistent in both catchments that the joint-calibration illustrates a marginally better match to the observed value than the streamflow calibration during most of the study period.

It is concluded that while the joint-calibration will typically lead to poorer streamflow forecast results during the calibration period, it could lead to a more robust result in the validation/forecasting period. As this was not consistently the case, more objective functions (such as unequal-weighted NS and a combination of several frequently-used objective functions) need to be investigated to identify the best calibration strategy for using soil moisture information.

Keywords: Hydrological model, calibration, soil moisture 
Yuxi Zhang et al., Towards operational hydrological model calibration using streamflow and soil moisture measurements

\section{INTRODUCTION}

Flood is threatening to human safety and causes damages to buildings and facilities. The effectiveness of preventing losses from floods mainly depends on the accuracy and precision of flood forecasts. Flood forecasting systems usually consist of several parts including model and database, post-processor, and alarm handling (Sene, 2008). Hydrologic models are the core component in the forecasting systems. Conceptual models, such as the PDM (Moore, 2007), the HBV model (Bergström and Singh, 1995), and the GR4J model (Perrin et al., 2003), are dominant in operational applications, due to their relatively robust forecasting skills compared with purely data-drive models and high efficiency compared with fully process-based models. The conceptual models typically require catchment-specific calibration to generate reliable forecasts. Traditionally, an objective function is defined for this purpose, being a numerical indication of the mismatch between the observed and simulated streamflow. This objective function is then minimized using techniques such as the Shuffled Complex Evolution method developed at The University of Arizona (Duan et al., 1992) (SCE-UA), simulated annealing (Eglese, 1990), genetic algorithms (Wang, 1991), or Particle Swarm Optimization (Eberhart and Kennedy, 1995).

Soil moisture is an important variable in the hydrologic cycle. In the study by Penna et al. (2011), it is noted that in wet condition, soil moisture acts as a clear threshold, above witch the generation of runoff is significantly increased. In recent years, the rapid development of earth observation satellites provides opportunities to obtain catchment-wide soil moisture information. These advanced soil moisture products provide a possibility to improve the current hydrological models by calibrating to both streamflow and soil moisture. Aubert et al. (2003) showed a significant improvement of streamflow simulation by using a joint calibration. More recently, Wanders et al. (2014) demonstrated that satellite soil moisture data does have positive impacts on the streamflow simulations for small catchments. However, the application of the newly developed soil moisture measurements in hydrologic models calibration is still under investigated.

OzNet hydrological monitoring network provides successive observations of soil moisture and precipitation of several catchments in Australia since 2001. Antecedent studies on the Adelong Creek and the Kyeamba catchments has done by Shahrban et al. (2015). This paper aims to study the feasibility of introducing soil moisture observations into hydrological model calibration, and evaluate the impact of the joint-calibration, compared with the traditional practice of calibrating hydrologic models using streamflow alone. A two-layer soil moisture based hydrological model (GRKAL) is used for this study, but only the soil moisture measurements of the entire zoot-zone layer are used for model calibration.

\section{METHODOLOGY}

\subsection{Study area and data}

\section{Study area}

To monitor long-term soil moisture, as well as meteorological dynamics, the OzNet hydrological monitoring network (www.oznet.org.au) (Smith et al., 2012) has been established in Murrumbidgee River basin. The Adelong Creek and the Upper Kyeamba Creek (Figure. 1) located in the southeast of the Murrumbidgee River basin are investigated. The Murrumbidgee basin is located in New South Wales in Australia, covering a total area of $84,000 \mathrm{~km}^{2}$, with the elevation ranging from more than $2,200 \mathrm{~m}$ to less than $50 \mathrm{~m}$. The area of Adelong and upper Kyeamba catchments are $157 \mathrm{~km}^{2}$ and $190 \mathrm{~km}^{2}$, respectively.

\section{Data}

Data used in this study include precipitation, potential evapotranspiration, stream discharge, and soil moisture. Precipitation and ground soil moisture measurements are obtained from the OzNet hydrological monitoring network. Five monitoring sites in the Adelong Creek Catchment and 5 sites in the upper Kyeamba Creek Catchment (out of 14 sites in the whole Kyeamba Creek Catchment) are used from February 2007 to December 2012. Precipitation and soil moisture data are averaged from $30 \mathrm{~min}$ time steps to hourly values to produce hourly forecasts. OzNet precipitation data are used only in the calibration period (Feb/2007-Dec/2010) within which the first 11 months (year 2007) are used as model spin-up. For the validation period (Jan/2011-Dec/2013), precipitation from Bureau of Meteorology (BoM) are used to make it to be consistent with operational forecasting scenarios (Shahrban et al., 2015). OzNet soil moisture data are adopted throughout the experiment duration. The hourly gauged stream discharge for the entire period (20072012) is obtained from New South Wales Office of Water. 
Yuxi Zhang et al., Towards operational hydrological model calibration using streamflow and soil moisture measurements

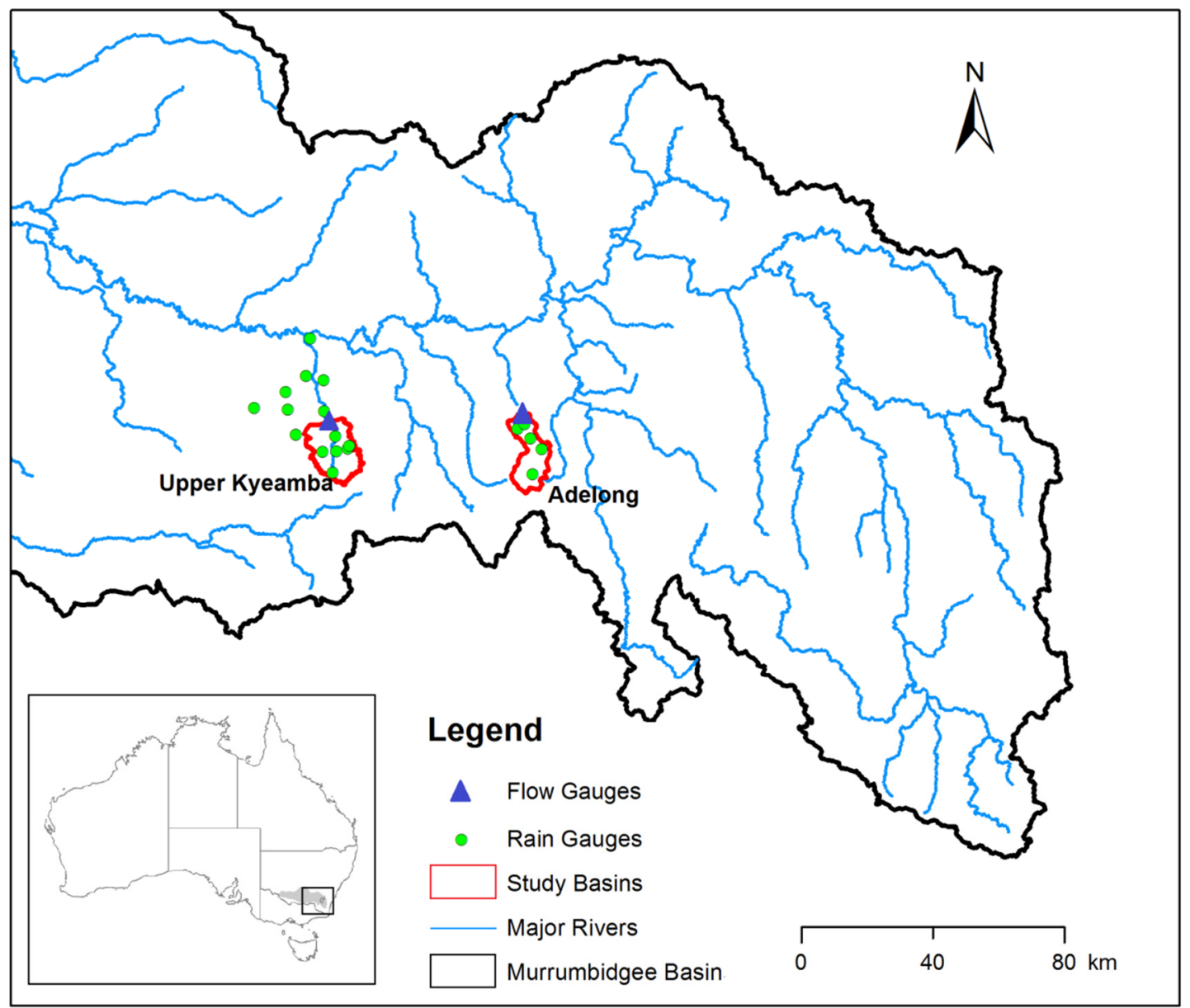

Figure. 1 Map of the catchments

\subsection{GRKAL model}

The GRKAL (Francois et al., 2003) model is a lumped conceptual rainfall-runoff model based on the GR4 (Perrin et al., 2003) and GRHUM (Loumagne et al., 1996) models. GR4 model has proven successful applying to 120 catchments in France and is accuracy when applied to small catchments (Loumagne et al., 1996). Different from GR4, the soil moisture of GRKAL model is parameterized as a two layer system - a surface layer and a deep layer. The conceptual structure of GRKAL model is shown in Figure. 2.

The net rainfall $P_{\mathrm{n}}$ entering the model is divided into two parts after passing an interception store: the part $P_{\mathrm{s}}$, which are then drained by means of evapotranspiration and percolation through a two-layer soil water storage, and the remaining part $P_{\mathrm{n}}-P_{\mathrm{s}}$ is the surface runoff, which then needs to be routed and which can also re-infiltrate. The percolation, converging with the re-infiltrated part of the surface runoff, is routed by two unit hydrographs, $U H 1$ and $U H 2$, which are allocated $90 \%$ and $10 \%$, respectively. The flow component routed by $U H 1$ then fills a nonlinear routing store. Both components are subject to a groundwater exchange term $F$. Finally the outflow $Q$ is the sum of the drainage of the routing store $Q_{\mathrm{r}}$ and the direct component $Q_{\mathrm{d}}$.

Eight parameters need to be calibrated: the maximum water capacity of surface $\left(w_{\text {sat }}\right)$ and deep ( $\left.w_{p \max }\right)$ soil layers; the coefficients $\left(\alpha_{1}\right.$ and $\left.\alpha_{2}\right)$ determining the partition of net rainfall; diffusivity coefficient $(d)$ between two layers; the maximum capacity of the roughing store $\left(w_{\mathrm{r}}\right)$; the coefficient $(\mathrm{x})$ determining the groundwater exchanges; and time base $(L)$ of the unit hydrographs.

\subsection{Calibration and validation}

The calibration experiments were carried out for the period from Feb/2007-Dec/2010 in two scenarios: 1) calibration using streamflow only and 2) joint-calibration using both streamflow and soil moisture measurements. For the streamflow-calibration scheme, the objective function to minimize the errors between 
Yuxi Zhang et al., Towards operational hydrological model calibration using streamflow and soil moisture measurements

observed and simulated data is the Nash-Sutcliffe model efficiency coefficient (NS), which can be mathematically expressed as

$$
\mathrm{NS}=1-\frac{\sum_{\mathrm{i}=1}^{\mathrm{n}}\left(\left(\mathrm{Q}_{\mathrm{obs}, \mathrm{i}}-\mathrm{Q}_{\text {sim }, \mathrm{i}}\right)^{2}\right.}{\sum_{\mathrm{i}=1}^{\mathrm{n}}\left(\left(\mathrm{Q}_{\mathrm{obs}, \mathrm{i}}-\overline{\mathrm{Q}}_{\mathrm{obs}, \mathrm{i}}\right)^{2}\right.}
$$

The range of Nash-Sutcliffe coefficient is $(-\infty, 1]$, where 1 means a perfect match of the simulated data to the observed data. A value of 0 indicates a knowledge-less model, that performs equally well as a time series equal to the mean of the observations at each time step. For the joint-calibration scheme, an equal-weighted NS was used as the objective function such that

$$
\mathrm{NS}=\frac{\sum_{\mathrm{i}=1}^{\mathrm{n}}\left(\mathrm{Q}_{\mathrm{obs}, \mathrm{i}}-\mathrm{Q}_{\mathrm{sim}, \mathrm{i}}\right)^{2}}{\sum_{\mathrm{i}=1}^{\mathrm{n}}\left(\mathrm{Q}_{\mathrm{obs}, \mathrm{i}}-\overline{\mathrm{Q}}_{\mathrm{obs}, \mathrm{i}}\right)^{2}}+\frac{\sum_{\mathrm{i}=1}^{\mathrm{n}}\left(\mathrm{SM}_{\mathrm{obs}, \mathrm{i}}-\mathrm{SM}_{\mathrm{sim}, \mathrm{i}}\right)^{2}}{\sum_{\mathrm{i}=1}^{\mathrm{n}}\left(\mathrm{SM}_{\mathrm{obs}, \mathrm{i}}-\overline{\mathrm{SM}}_{\mathrm{obs}, \mathrm{i}}\right)^{2}}
$$

where $\mathrm{SM}_{\mathrm{obs}}$ and $\mathrm{SM}_{\text {sim }}$ are soil wetness (\%) of the entire zoot-zone layer.

In the validation stage (Jan/2011-Dec/2013), the model is applied with the parameters derived from the calibration. The simulated streamflow of both scenarios are evaluated by the Nash-Sutcliffe using equation (1).

\section{RESULTS}

\subsection{Outcomes A: Streamflow}

The observed and simulated streamflow of each scenario are illustrated in Figure. 3 and Figure. 4 for both the calibration and validation periods. It can be inferred from Figure. 3 that, for the Adelong catchment, the joint-calibration results in a slightly worse match of the peak flows than the streamflowonly calibration in the calibration period, whilst the performance is slightly better during the validation period.

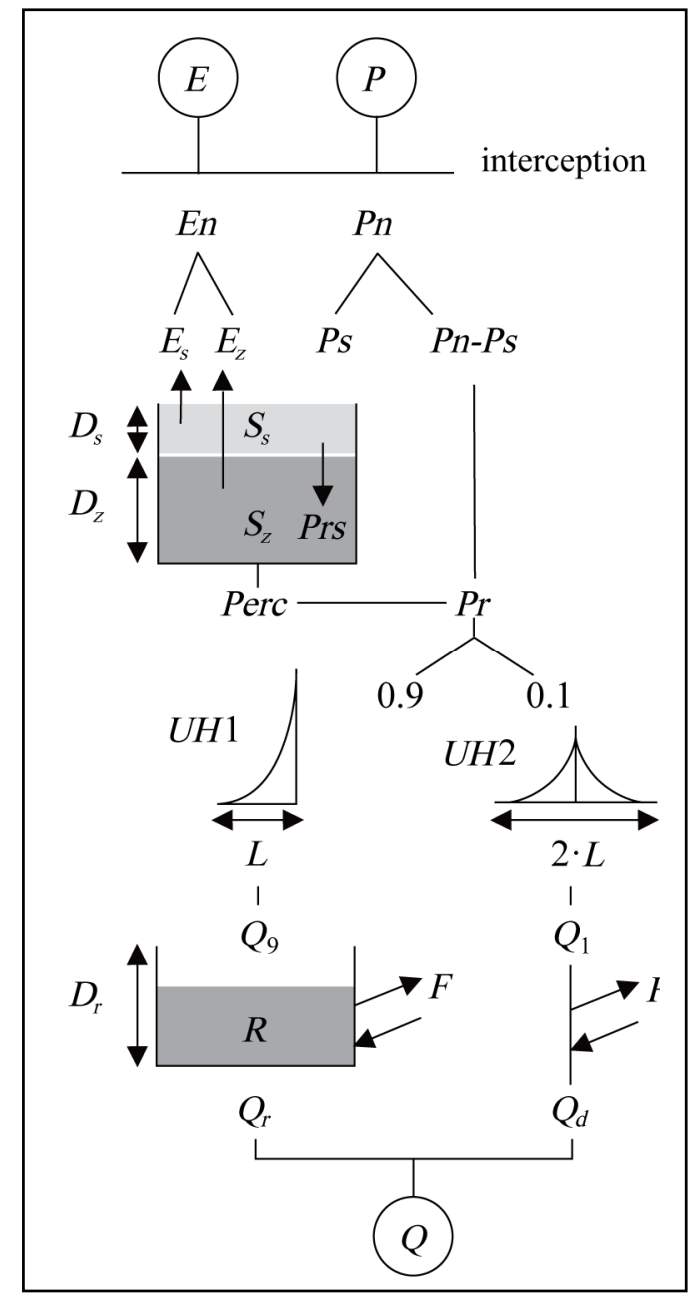

Figure. 2 Structure of the GRKAL model (Francois et al., 2003).

Table 1 lists the calculated Nash-Sutcliffe values for both the streamflow-only and joint calibrations during the calibration and validation periods. It is shown that the joint-calibration for Adelong catchment displays a lower NS value during the calibration period, but a higher NS value during the validation period. However, the NS values in joint-calibration case are consistently lower in both calibration and validation periods.

Table 1 Nash-Sutcliffe values for Adelong catchment

\begin{tabular}{|c|c|c|c|c|}
\hline \multirow{2}{*}{} & \multicolumn{2}{|c|}{ Adelong Catchment } & \multicolumn{2}{c|}{ Kyeamba Catchment } \\
\cline { 2 - 5 } & Cal. & Val. & Cal. & Val. \\
\hline Q-cal. & 0.8443 & 0.7586 & 0.6936 & 0.6925 \\
\hline joint-cal. & 0.8173 & 0.7952 & 0.6701 & 0.6402 \\
\hline
\end{tabular}

\subsection{Outcomes B: Soil moisture}

It is physically intuitive that the calibration involving soil moisture observations would improve the corresponding soil moisture simulation result. This is proven by Figure. 5 and Figure. 6, in which the entire zoot-zone soil wetness $(0-1 \mathrm{~m})$ simulations of the two scenarios are compared to the observations. It can be clearly seen that joint-calibration illustrates a better match to the observed data during most of the study period. 
Yuxi Zhang et al., Towards operational hydrological model calibration using streamflow and soil moisture measurements
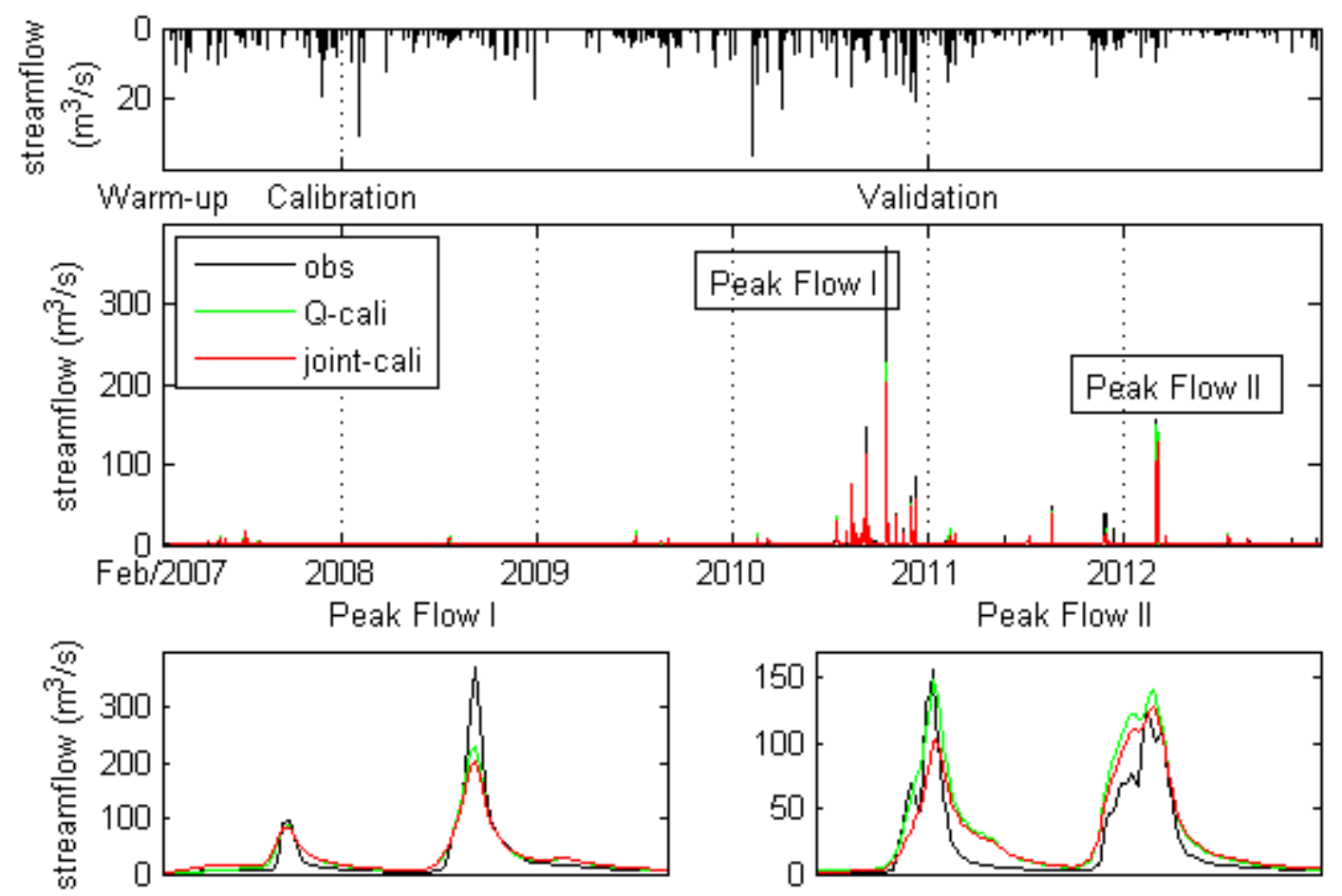

Figure. 3 Simulated and observed streamflow for the Adelong catchment.

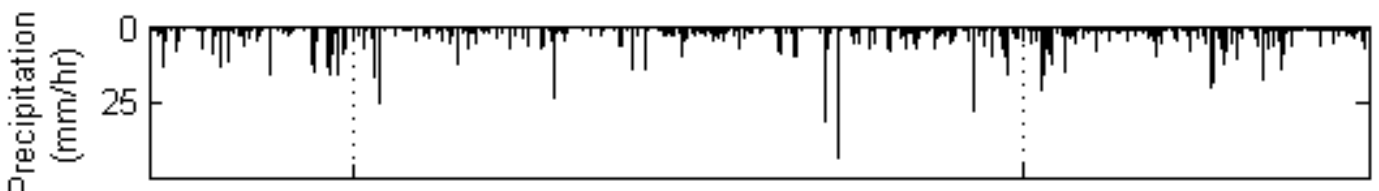

는

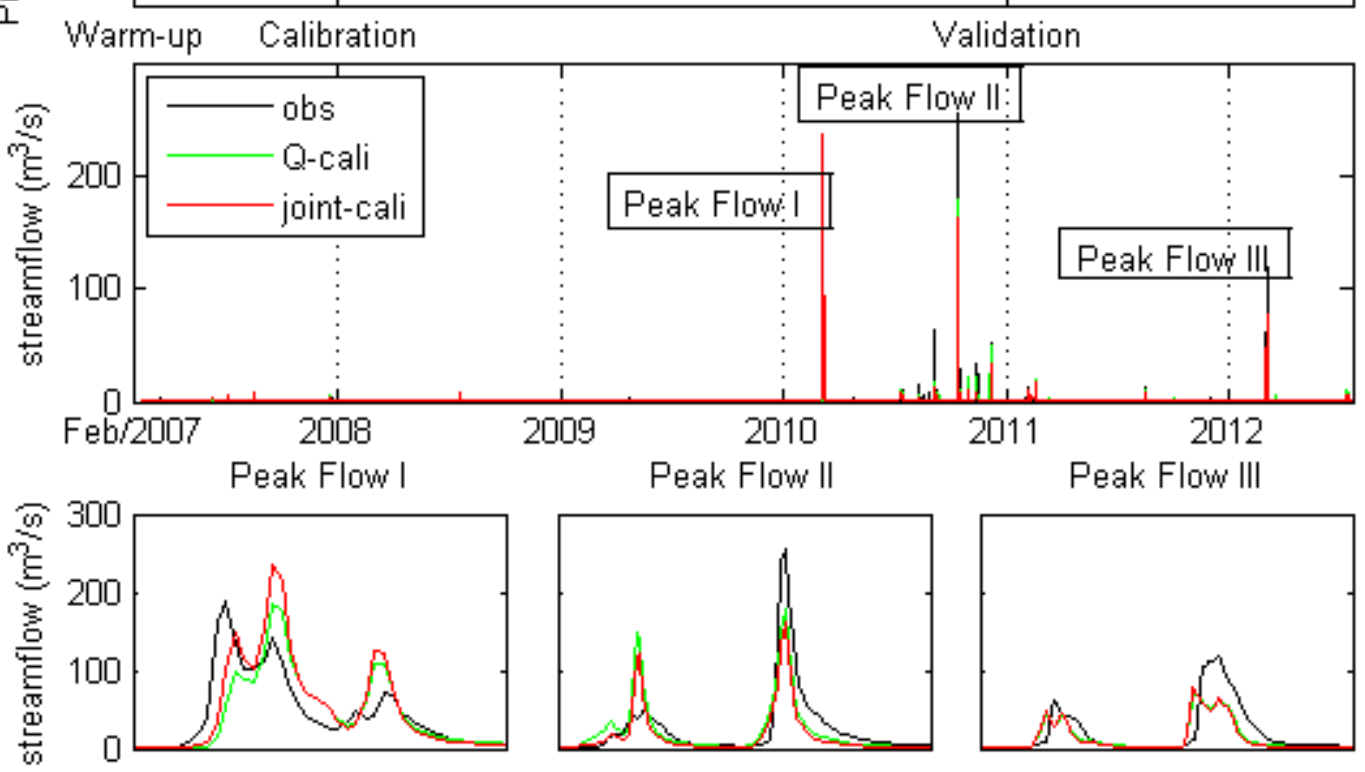

Figure. 4 Simulated and observed streamflow for the Kyeamba catchment.

\subsection{Discussion}

The difference in model performance is a result of the different parameter sets obtained by introducing soil moisture in the calibration or not. It is obvious that including soil moisture information can marginally improve soil moisture simulation so as to impact future streamflow forecasts. This impact on streamflow forecasts can be positive as seen from the results in Adelong Creek. This can be explained that although the errors are not minimal in streamflow in the joint-calibration scenario, it may give a better parameter set 
Yuxi Zhang et al., Towards operational hydrological model calibration using streamflow and soil moisture measurements

which better captures the water propagation and flow dynamics. The streamflow forecasts can potentially benefit from more realistic parameter sets and better characterized initial soil moisture conditions. However, although this phenomenon is logical in theory, it is not always consistent in practice, as opposite results are obtained in Kyeamba catchment. This indicates that soil moisture information can help to improve model performance, only when the simulation and observation are properly combined, and the model can properly represent the relationship between soil moisture and runoff generation/infiltration process. Further investments on the choice of objective function (e.g. unequal-weighted NS) can be done in the future to use soil moisture information in an optimal way.

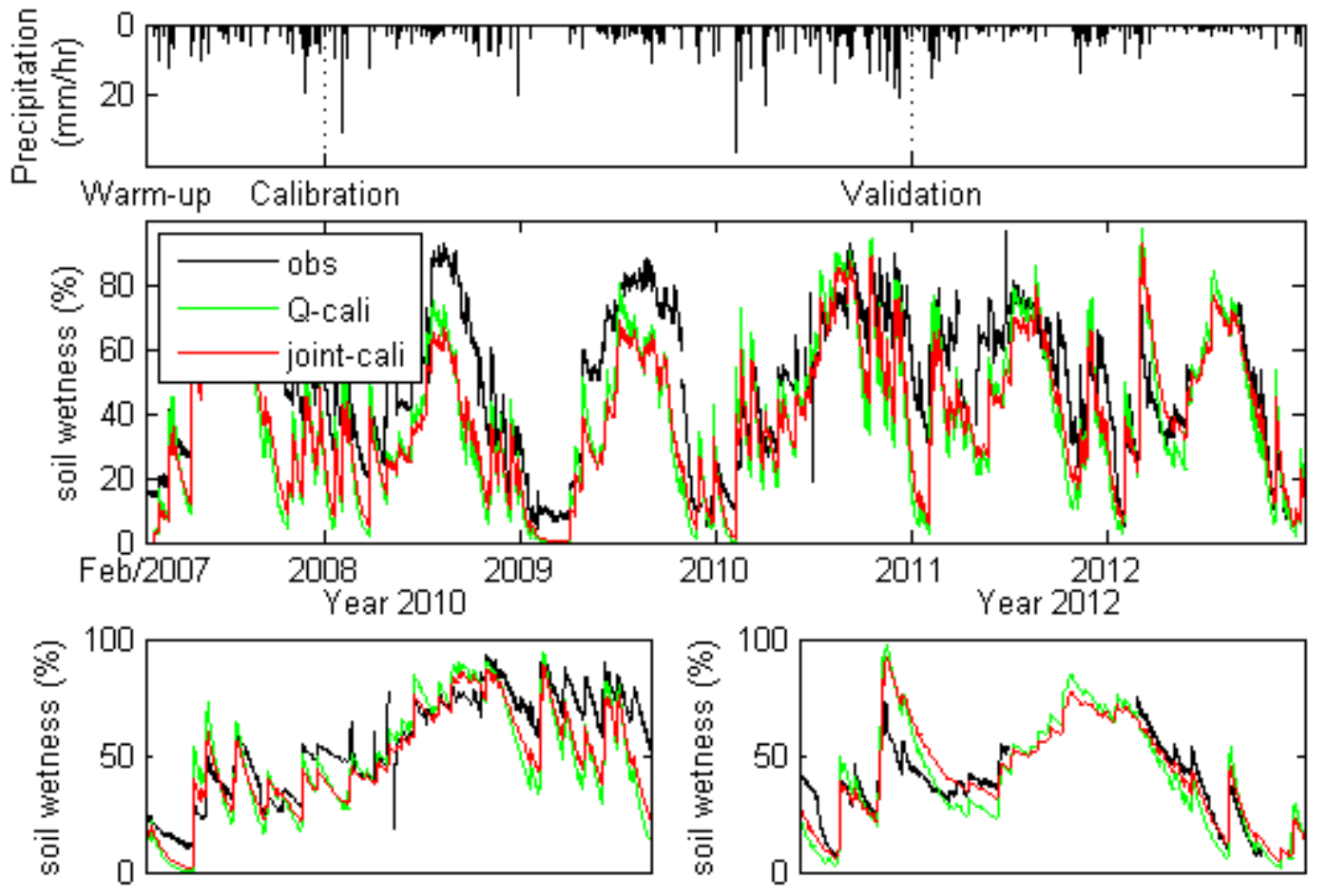

Figure. 5 Simulated and observed soil moisture of the Adelong catchment.
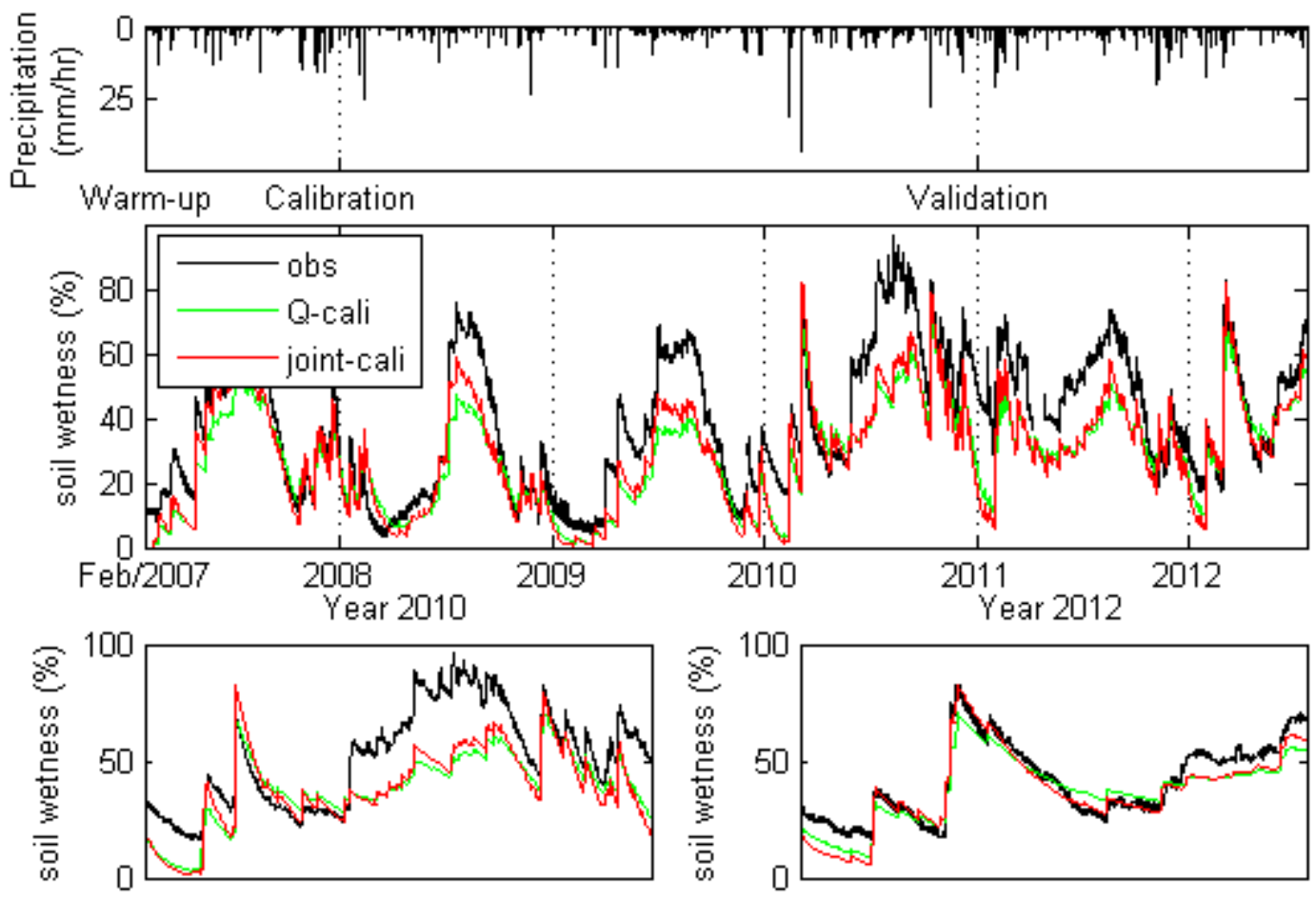

Figure. 6 Simulated and observed soil moisture of the Kyeamba catchment. 
Yuxi Zhang et al., Towards operational hydrological model calibration using streamflow and soil moisture measurements

\section{CONCLUSTIONS}

Two calibration scenarios, streamflow-only calibration and joint streamflow-soil moisture calibration, were applied to the Adelong and Kyeamba catchments, leading to different model performances. The simulated streamflow and soil moisture are compared to observations and are quantitatively evaluated using the NashSutcliffe coefficient.

It is concluded that although the joint-calibration will typically lead to a lower Nash-Sutcliffe value during the calibration period, it has the possibility to result in a more robust result in the validation/forecasting period. However, this potential is not consistent in practical applications and needs to be further investigated by incorporating different objective in order to identify the best calibration strategy when using soil moisture information for flood forecasting models.

\section{ACKNOWLEDGMENTS}

This study has been conducted within an Undergraduate Summary Research Program co-funded by Monash University and the Bushfires \& Natural Hazards CRC - Improving flood forecast skill using remote sensing data.

\section{REFERENCES}

Aubert, D., Loumagne, C., Oudin, L., 2003. Sequential assimilation of soil moisture and streamflow data in a conceptual rainfall-runoff model. Journal of Hydrology 280(1) 145-161.

Bergström, S., Singh, V., 1995. The HBV model. Computer models of watershed hydrology. 443-476.

Duan, Q., Sorooshian, S., Gupta, H.V., 1992. Effective and efficient global optimization for conceptual rainfall-runoff models. Water Resources Research 28(4) 1015-1031.

Eberhart, R.C., Kennedy, J., 1995. A new optimizer using particle swarm theory, Proceedings of the sixth international symposium on micro machine and human science. New York, NY, pp. 39-43.

Eglese, R.W., 1990. Simulated annealing: A tool for operational research. European Journal of Operational Research 46(3) 271-281.

Francois, C., Quesney, A., Ottlé, C., 2003. Sequential assimilation of ERS-1 SAR data into a coupled land surface-hydrological model using an extended Kalman filter. Journal of Hydrometeorology 4(2) 473-487.

Loumagne, C., Chkir, N., Normand, M., Ottlé, C., Vidal-Madjar, D., 1996. Introduction of the soil/vegetation/atmosphere continuum in a conceptual rainfall/runoff model. Hydrological Sciences Journal 41(6) 889-902.

Moore, R., 2007. The PDM rainfall-runoff model. Hydrology and Earth System Sciences Discussions 11(1) 483-499.

Penna, D., Tromp-van Meerveld, H., Gobbi, A., Borga, M., Dalla Fontana, G., 2011. The influence of soil moisture on threshold runoff generation processes in an alpine headwater catchment. Hydrology and Earth System Sciences 15(3) 689-702.

Perrin, C., Michel, C., Andréassian, V., 2003. Improvement of a parsimonious model for streamflow simulation. Journal of Hydrology 279(1-4) 275-289.

Sene, K., 2008. Flood Warning, Forecasting and Emergency Response. Springer, Berlin, London.

Shahrban, M., Walker, J.P., Wang, Q.J., Robertson, D., 2015. Evaluation of rainfall-runoff modelling and soil moisture estimation in the Murrumbidgee catchment. In preparation.

Smith, A.B., Walker, J.P., Western, A.W., Young, R.I., Ellett, K.M., Pipunic, R.C., Grayson, R.B., Siriwardena, L., Chiew, F.H.S., Richter, H., 2012. The Murrumbidgee soil moisture monitoring network data set. Water Resources Research 48(7) W07701.

Wanders, N., Bierkens, M.F.P., de Jong, S.M., de Roo, A., Karssenberg, D., 2014. The benefits of using remotely sensed soil moisture in parameter identification of large-scale hydrological models. Water Resources Research 50(8) 6874-6891.

Wang, Q.J., 1991. The Genetic Algorithm and Its Application to Calibrating Conceptual Rainfall-Runoff Models. Water Resources Research 27(9) 2467-2471. 